\title{
SHEAR REINFORCEMENT OF REINFORCED CONCRETE INELASTIC INTERIOR BEAM-COLUMN JOINTS
}

\author{
by \\ T. Ichinose*
}

\begin{abstract}
"Equilibrium of forces" is the principle used in the current New Zealand code requirements for shear reinforcement of beam column joint. This principle, however, yields irrational or empirical aspects of the current code requirements. The latter principle as well as a simplification of stress distribution along the periphery of the joint can yield a design equation to calculate the necessary amounts of shear reinforcement in inelastic interior joint. Normally, this design equation requires smaller amounts of shear reinforcement than the current New Zealand code, especially for the following cases:
\end{abstract}

a) the joint shear stress is small,

b) the axial force is small,

c) the amount of top beam reinforcement is larger than at the bottom, and

d) the amounts of vertical shear reinforcement is large.

\section{IRRATIONAL ASPECTS OF CURRENT NZ CODE}

The current New Zealand code for concrete structures, NZS 3101:1982(1), requires that the horizontal shear reinforcement within a beam column joint must carry the total joint shear force unless the axial force of the column is large enough or the plastic hinge regions of the beams are relocated away from the column faces. This requirement is based on the theory of truss and strut actions proposed by Paulay et al (2).

This requirement has raised international arguments. Park et al (3) conducted a test on a specimen which satisfied the requirement, and concluded that the requirement was not overly conservative. on the other hand, Kitayama et al $(4,5)$ also conducted an experiment on a specimen which satisfied the requirement, and concluded that one half of the shear reinforcement required by the New Zealand code was enough to keep the shear reinforcement in the joint elastic after reversed cyclic loading to a large deflection angle. The specimens of both experiments had many similarities: small axial load, large ratio of column depth to beam bar diameter, etc. The largest difference between the specimens was, in the author's view, that the ratio of the amount of the top beam reinforcement to that of the bottom $\left(\mathrm{A}_{\mathrm{st}} / \mathrm{A}_{\mathrm{sb}}\right)$ was 2 in Kitayama's specimen, whereas, in Park's

Research Associate, Department of Architecture, Nagoya Institute of Technology, Nagoya 466, Japan. specimen, the ratio was 1 .

The author believes that Paulay's theory (2) includes limitations which yield irrational or empirical aspects of NZS 3101 as follows:

[1] Current design equation for inelastic joint to evaluate the contribution of concrete to the horizontal joint shear strength is not based on the theory of truss and strut action. It utilizes an empirical equation for shear design of beam and column.

[2] Current equation for inelastic joint ignores the effects of the difference between the amount of top and bottom beam reinforcement. When the amounts of top beam reinforcement are larger than at the bottom, the flexural concrete compressive stresses in the beams will not completely diminish after inelastic load reversals. This will have favourable effects compared with the case of equal top and bottom beam reinforcement.

[3] Current design equation gives the amount of horizontal shear reinforcement regardless of the amount of vertical shear reinforcement present. However, they must be related to each other. The amount of the intermediate longitudinal reinforcement in a column will often be larger than the required amount of vertical joint shear reinforcement. The excess of the vertical shear reinforcement can decrease the necessary amount of horizontal shear reinforcement. 
All these irrational aspects indicate the limitation of the basis of current equations, "the principle of equilibrium of inner forces". A force polygon of inner forces may correctly represent an equilibrium of stresses for a few special cases, but not necessarily for all the cases.

The objective of this paper is to develop a design equation for joint shear reinforcement based on the princjple of equilibrium of stresses. This design equation will overcome these irrational aspects.

\section{SCOPE AND ASSUMPTIONS}

This paper deals with a one way interior joint as shown in Fig. 1. Area of left and right column bars is assumed to be the same. Area of top beam bars is assumed to be equal to or larger than bottom beam bars $\left(A_{s t}>A_{s b}\right)$. Prestressing steel is not considered.
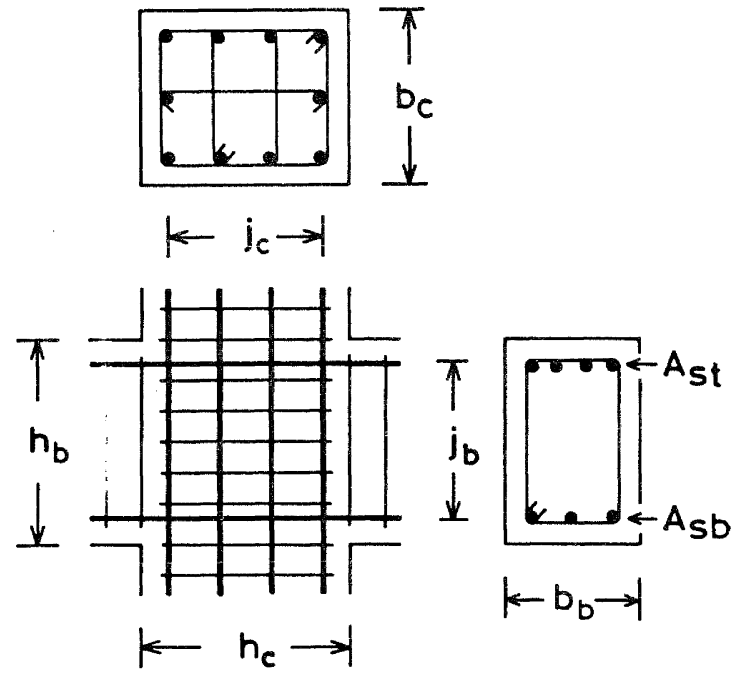

FIG. 1 - CONFIGURATION OF JOINT CONSIDERED

Stress distributions along the periphery of the joint are modelled as shown in Fig. 2: in other words, the following assumptions are made. Statements shown in [ ] indicate the effects or the results of the assumptions.

(a) Anchorage of beam bars is good enough within the joint. [This assumption requires that the beam bars carry as much stress as possible up to their overstrength, $\lambda f_{y}(\lambda=$ steel strength enhancement factor and $\mathrm{f}_{\mathrm{y}}=$ yield strength), both in tension and in compression.] The forces in the top and bottom beam bars, $\mathrm{T}_{1}, \mathrm{~T}_{2}, \mathrm{C}_{\mathrm{s} 1}$ and $\mathrm{C}_{\mathrm{s} 2}$, are given by the following equations.

$$
\begin{aligned}
& \mathrm{T}_{1}=\mathrm{A}_{\mathrm{st}} \lambda \mathrm{f}_{\mathrm{y}} \\
& \mathrm{T}_{2}=\mathrm{C}_{\mathrm{s} 1}=\mathrm{C}_{\mathrm{s} 2}=\mathrm{A}_{\mathrm{sb}} \lambda \mathrm{f}_{\mathrm{y}}
\end{aligned}
$$

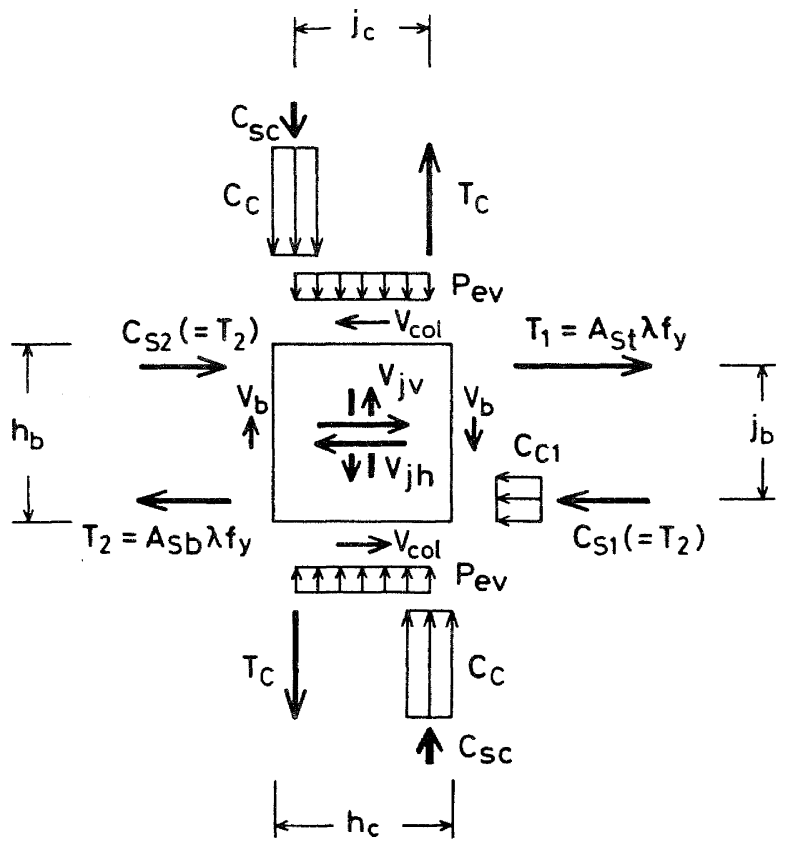

FIG. 2 - ASSUMED STRESSES ALONG THE PERIPHERY OF A JOINT

This assumption implies that the concrete near the upper face of the beam does not carry any compressive force (2). The compressive force of beam concrete at the bottom, $\mathrm{C}_{\mathrm{Cl}}$, is given by the following equation:

$$
C_{c l}=T_{1}-T_{2}
$$

The horizontal joint shear force, $V_{j h}$, is

$$
\mathrm{V}_{j h}=\mathrm{T}_{1}+\mathrm{T}_{2}-\mathrm{v}_{\mathrm{col}}
$$

(b) Compressive stresses of the beam concrete near the bottom face are uniformly distributed. The centroid of the compressive stresses is assumed to coincide with the location of the bottom beam bar.

(c) Shear forces from the left and right beams are the same. Shear forces introduced by the top and bottom columns are also the same.

(d) Forces in the tensile and compressive column bars, $\mathrm{T}_{\mathrm{C}}$ and $\mathrm{C}_{\mathrm{SC}}$, are calculated by assuming that the column section remains plane after deformation and by assuming an appropriate stress-strain model for concrete. Contributions of the intermediate column bars to flexural strength are ignored in this analysis. The intermediate column bars are assumed to serve as the vertical shear reinforcement only. 
[Therefore, forces of intermediate column bars do not appear in Fig. 2.]

(e) Compressive stresses of column concrete are assumed to consist of the following two components.

1. Concentric uniform compressive stress over the distance of $j_{C}$. The resultant of these stresses is $\mathrm{P}_{e v}$ in Fig.2.

2. Eccentric uniform compressive stress, the centroid of which almost coincides with

the location of the compressive column bars.

The resultant of the stresses is $\mathrm{C}_{\mathrm{C}}$ in $\mathrm{Fig} .2$.

[The distribution of concrete compressive stresses resulting from this assumption might be considerably different from that obtained by the plane section analysis which was utilized to calculate the forces in the column bars. However, the values of $\mathrm{P}_{\mathrm{ev}}$ and $\mathrm{C}_{\mathrm{c}}$ can be estimated by the equations in the following paragraph to represent correctly the concentric component and the eccentric component of the stress distribution of the plane section analysis. Thus, this assumption is justified.]

The assumptions (b), (d) and (e) lead to the following equation for the vertical joint shear force, $v_{j} v$.

$$
v_{j v}=\left(j_{b} / j_{c}\right) v_{j h}
$$

The eccentric component of compressive concrete force, $C_{C}$, can be calculated by the following equation, which is derived from assumptions (c) and (e) and it includes the vertical shear force.

$$
\mathrm{C}_{\mathrm{c}}=\mathrm{v}_{j \mathrm{v}}-\mathrm{T}_{\mathrm{c}}+\mathrm{V}_{\mathrm{b}}-\mathrm{C}_{\mathrm{sc}}
$$

The concentric component of compressive concrete force, $\mathrm{P} e v$, can be calculated by the following equation, which is derived from assumptions (c), (d) and (e) and include the axial force.

$$
\begin{aligned}
P_{e v} & =P_{e}+T_{c}-C_{c}-C_{s c} \\
& =P_{e}+2 T_{c}-V_{b}-V_{j v}
\end{aligned}
$$

In addition to the assumptions (a) to (e) shown in Fig. 2, the following assumptions are made:

(f) Bond forces of beam bars are uniformly distributed over the length of $j_{c}$ as shown in Fig. 3. Bond forces along the column bars are also uniformly distributed over the length of $j_{b}$.

(g) Concrete carries no tensile stress, but it may carry infinite compressive stresses. [The objective of this paper is limited to develop an equation to calculate the necessary amount of joint shear reinforcement. So a compressive failure of joint concrete is not considered.]

\section{SHEAR RESISTING ACTIONS}

The following three actions are considered.

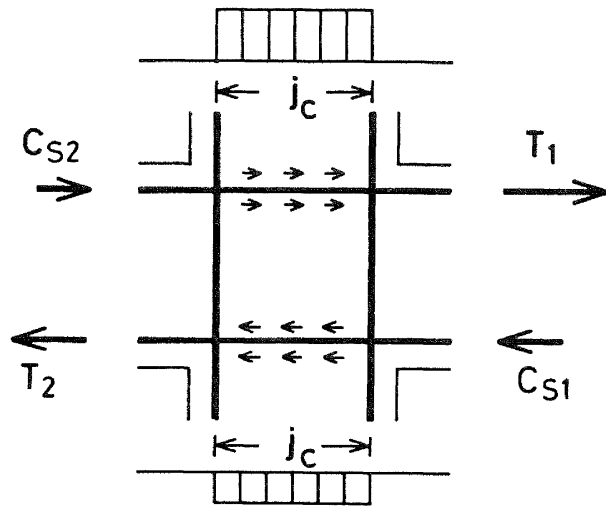

FIG. 3 - ASSUMED DISTRIBUTION OF BOND FORCE ALONG BEAM BARS WITHIN A JOINT

(1) Truss action defined in Fig. 4, where

$\mathrm{V}_{\mathrm{sv}}$ is the hoop action induced by the vertical joint shear reinforcement,

$\mathrm{V}_{\text {th }}$ is a part of the hoop action induced by the horizontal shear reinforcement,

$P$ is the concentric component of the compressive concrete stress from the columns,

$Q_{t r}$ in the horizontal direction is a part of $\left(\mathrm{T}_{1}+\mathrm{T}_{2}-\mathrm{V}_{\mathrm{CO}}\right)$ and $\left(2 \mathrm{~T}_{2}-\mathrm{V}_{\mathrm{CO}}\right)$, the bond force transferred from the top and bottom beam bars less the shear force transferred from the column,

$\left(j_{b} / j_{c}\right) Q_{t r}$ in the vertical direction equals $\left(T_{C}+C_{S C}-V_{b}\right)$, the bond force transferred from the left and right column bars less the shear force transferred from the beams. This definition leads to

$Q_{t r}=\left(j_{c} / j_{b}\right)\left(T_{c}+c_{s c}-v_{b}\right)$

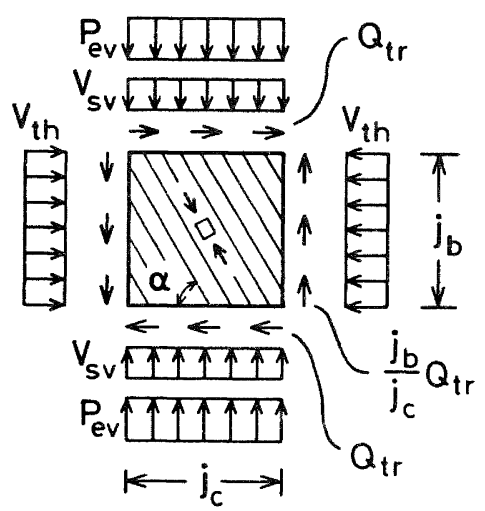

FIG. 4 - TRUSS ACTION 
The value of $V_{t h}$ is given by the following equation because the principle tensile stress of concrete must be zero as shown by Mohr's stress of Fig. 5.

$$
v_{t h}=\frac{j_{b}}{j_{c}} \frac{Q_{t r}^{2}}{\left(P_{e v}+V_{s v}\right)^{2}}
$$

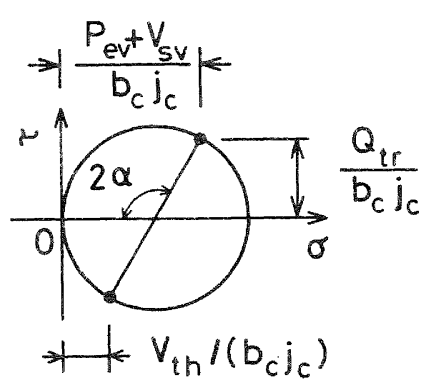

FIG. 5 - MOHR'S STRESS CIRCLE FOR TRUSS ACTION

(2) Quasi strut action A defined by Fig. 6,

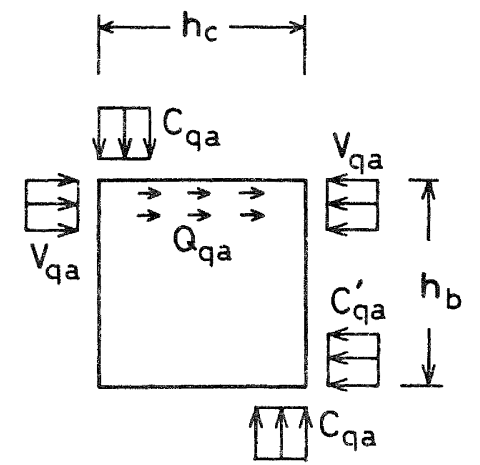

FIG. 6 - QUASI STRUT ACTION A

where

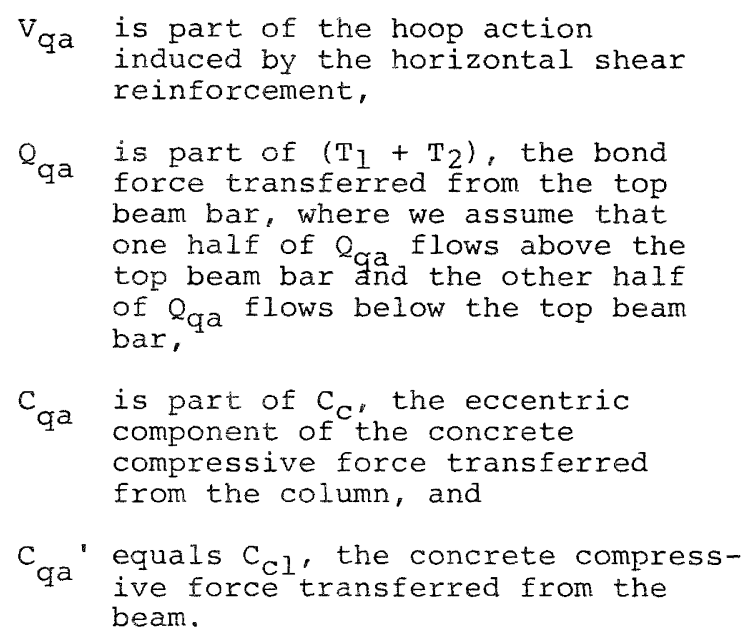

The equilibrium of forces requires that

$$
\mathrm{V}_{\text {qa }}=Q_{\text {qa }}=\mathrm{C}_{\text {qa }}{ }^{\prime}=\mathrm{C}_{\mathrm{Cl}}=\mathrm{T}_{1}-\mathrm{T}_{2}
$$

This action can be decomposed into two actions: the strut action (diagonal compression) shown in Fig. $7(a)$ and the bond action (horizontal compression) shown in Fig. 7(b). It appears unrealistic to assume that hoop action $\mathrm{V}_{\mathrm{q}}$, works directly on the beam face as shown in Fig. 7(a) as long as the horizontal joint shear reinforcement consists of hoops enclosing column bars. This assumption will be justified in Appendix 1.

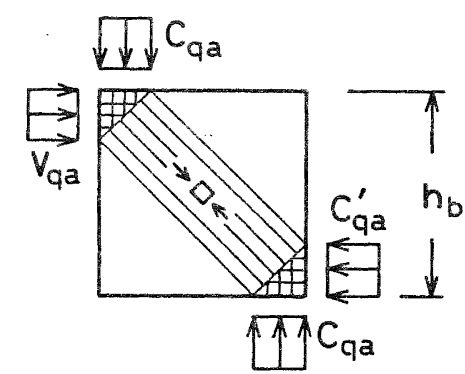

(a) Strut Action

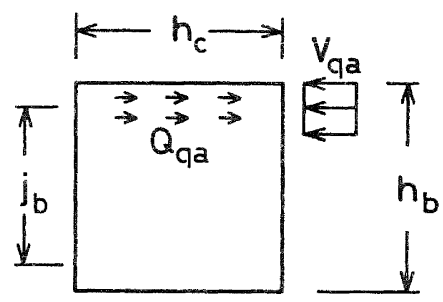

(b) Bond Action

FIG. 7 - DECOMPOSITION OF QUASI STRUT ACTION A

(3) Quasi strut action B defined by Fig.8,

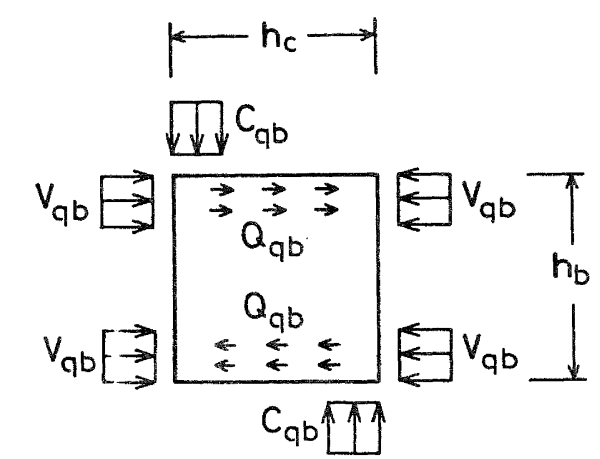

FIG. 8 - QUASI STRUT ACTION B 
where

$\mathrm{V}_{\mathrm{qb}}$ is the remaining part of the hoop action induced by the horizontal shear reinforcement,

$Q_{q b}$ is the remaining part of the bond force transferred from the top and bottom beam bars less the shear force transferred from the columns $\left(=\mathrm{T}_{1}+\mathrm{T}_{2}-\mathrm{V}_{\mathrm{CO}}-\mathrm{Q}_{\mathrm{tr}}-\mathrm{V}_{\mathrm{ga}}\right)$ where we assume that one half of $Q_{\text {gb }}$ flows above the top and below the bottom beam bar and the other half of $Q_{\text {gb }}$ flows below the top and above the bottom beam bar, and

$\mathrm{C}_{\mathrm{qb}}$ is the remaining part of the concrete compressive force transferred from the column.

The equilibrium of forces requires that

$$
\begin{aligned}
V_{q b} & =Q_{q b}=T_{1}+T_{2}-V_{c o l}-Q_{t r}-V_{q a} \\
& =2 T_{2}-V_{c o l}-Q_{t r} \\
& =2 T_{2}-V_{c o l}-\left(j_{c} / j_{b}\right)\left(T_{c}+C_{s c}-V_{b}\right)
\end{aligned}
$$

This action can be decomposed into two actions: the strut action (diagonal compression) shown in Fig. 9(a) and the bond action (horizontal compression) shown in Fig. 9(b). The right side of the equation (11) can be negative when the forces in the bottom beam bars are considerably smaller than those in the column bars. In such a case, we should consider another shear resisting action. However, such a case would be almost impossible under the current requirement that $A_{\text {st }}<2 . A_{s b}$.

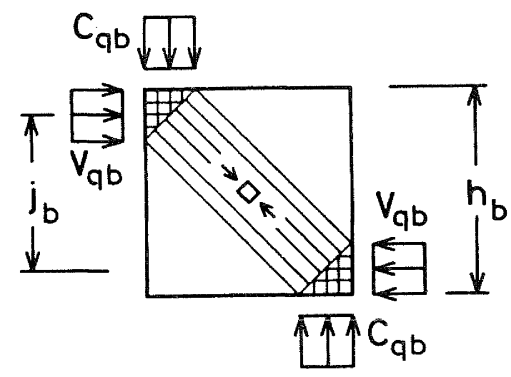

(a) Strut Action

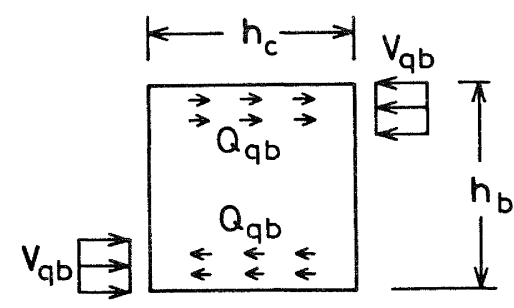

(b) Bond Action

FIG. 9 - DECOMPOSITION OF QUASI STRUT ACTION ACTION B
It should be noted that the sum of equations (8), (10) and (11) gives the total horizontal joint shear force, $v_{j h}$.

$$
Q_{t r}+Q_{q a}+Q_{q b}=V_{j h}
$$

\section{DESIGN EQUATION}

If we simply add all the horizontal hoop actions required in the three shear resisting mechanisms listed above, we obtain the necessary amount of horizontal joint shear reinforcement.

$$
\mathrm{v}_{\mathrm{sh}}=\mathrm{v}_{\mathrm{qa}}+2 \mathrm{v}_{\mathrm{qb}}+\mathrm{v}_{\mathrm{th}}
$$

We define the horizontal joint shear reinforcement as the hoops placed between the top and bottom beam bars. This definition leads to equation (14) which gives the necessary amount of horizontal joint shear reinforcement. The remaining hoop actions, $\left(\mathrm{v}_{\mathrm{ga}}+\mathrm{V}_{\mathrm{gb}}\right) / 2$ above the top beam bar and $v_{\mathrm{gb}} / 2$ below the bottom beam bar, are assumed to be carried by the hoops in the columns above and below the joint, respectively. This assumption will be discussed in Appendix 2.

$$
\mathrm{v}_{\mathrm{sh}}=\mathrm{v}_{\mathrm{qa}} / 2+\mathrm{v}_{\mathrm{qb}}+\mathrm{v}_{\mathrm{th}}
$$

Substituting $V_{t h}$ in the equation (8) into equation (14) yields

$v_{s h}=v_{q a} / 2+v_{q b}+\frac{j_{b}}{j_{c}} \frac{Q_{t r}}{\left(P_{e v}+V_{s v}\right)}$

Substituting $\mathrm{V}_{\mathrm{qa}}, \mathrm{V}_{\mathrm{qb}}$ and $Q_{\mathrm{tr}}$ from the equations (10), (11) and (8) into Eq. (15) gives the following design equation to calculate the necessary amount of horizontal joint shear reinforcement:

$$
\begin{aligned}
V_{s h} & =\frac{T_{1}+3 T_{2}}{2}-V_{c o l} \\
& -\frac{j_{c}}{j_{b}}\left(T_{c}+c_{s c}-V_{b}\right)\left(1-\frac{T_{c}+C_{s c}-V_{b}}{\left(P_{e v}+V_{s v}\right.}\right)
\end{aligned}
$$

In order to compare the above equation with the current $\mathrm{NZ}$ code requirements, let us consider the case when:

$$
\begin{aligned}
& j_{c}=j_{b}, \\
& T_{c}=\left(T_{1}+T_{a}\right) / 2 \text {, and } \\
& c_{s c^{\prime}} v_{b} \text { and } v_{c o l} \text { are much smaller than } \\
& v_{j h} \cdot
\end{aligned}
$$

then, equation (16) reduces to

$$
\frac{V_{s h}}{V_{j h}}=\frac{A_{s b}}{A_{s t}+A_{s b}}-\frac{V_{j h}}{4\left(P_{e}+V_{s v}\right)}
$$

This relationship is presented in Fig. 10 by the bold continuous or broken line for the case of $\mathrm{A}_{\mathrm{st}} / \mathrm{A}_{\mathrm{sb}}=1$ or 2 , respectively. values given $\mathrm{b}_{\mathrm{Y}}^{\mathrm{t}}$ the current code (1) are presented by the fine lines for the case of 


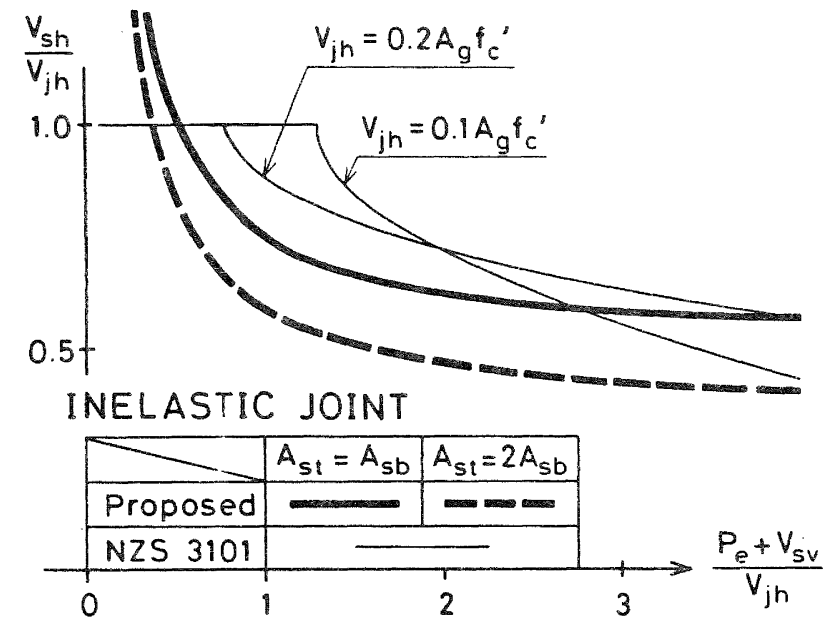

FIG. 10 - RATIO OF REQUIRED HORIZONTAL JOINT SHEAR REINFORCEMENT TO TOTAL JOINT SHEAR FORCE FOR THE CASE WHEN $j_{c}-j_{b} m T_{c}=\left(T_{1}+T_{2} / 2, C_{s c} \ll\right.$ $v_{j h}, v_{c o l} \ll v_{j h}$ and $v_{b} \ll v_{j h}$

$f_{\dot{C}}^{\prime}=40 \mathrm{MPa}$. This figure implies that in most situations the proposed equation requires less shear reinforcement than the current code.

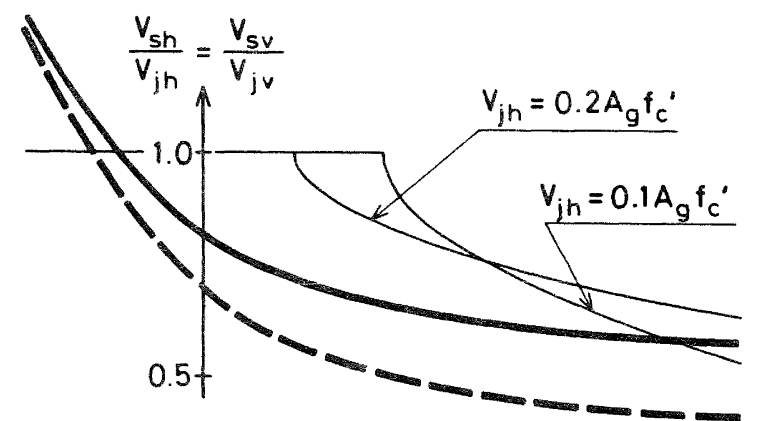

INELASTIC JOINT

\begin{tabular}{|c|c|c|}
\hline $\bar{F}$ & $A_{s t}=A_{s b}$ & $A_{s t}=2 A_{s b}$ \\
\hline Proposed & & $-\infty$ \\
\hline NZS 3101 & & 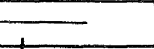 \\
\hline-1 & 0 & i \\
\hline
\end{tabular}

FIG. 11 - RATIO OF REQUIRED HORIZONTAL JOINT SHEAR REINFORCEMENT TO TOTAL JOINT SHEAR FORCE FOR THE CASE WHEN $\mathrm{V}_{\text {Sh }}=$ $\mathrm{V}_{\mathrm{SV}}, j_{\mathrm{C}}=\mathrm{j}_{\mathrm{b}}, \mathrm{T}_{\mathrm{C}}=\left(\mathrm{T}_{1}+\mathrm{T}_{2}\right) / 2$ $\mathrm{C}_{\mathrm{sc}} \ll \mathrm{V}_{j h^{\prime}} \mathrm{V}_{\mathrm{col}}<<\mathrm{V}_{j h}$ and $\mathrm{V}_{\mathrm{b}}<<\mathrm{V}_{j h}$
According to the proposed design equation, it is possible to make the amount of the horizontal shear reinforcement the same as that of the vertical. Substituting $V_{S h}=V_{S V}$ into the equation (17) and separating the variables yields

$$
\begin{aligned}
& \frac{v_{s h}}{V_{j h}}=\frac{V_{s v}}{V_{j h}}=\frac{1}{2}\left[\frac{A_{s b}}{A_{s t}+A_{s b}}-\frac{P_{e}}{V_{j h}}\right. \\
&\left.+\sqrt{\left(\frac{P_{e}}{V_{j h}}+\frac{2 A_{s b}}{A_{s t}+A_{s b}}\right)+I}\right]
\end{aligned}
$$

This relationship is shown in Fig. 11. This figure implies that the amount of horizontal joint shear reinforcement need not be equal to the total joint shear force even when the axial force is zero.

\section{VERIFICATION OF THE PROPOSED EQUATION}

Because the proposed design equation is based on the assumption that the anchorage of the beam bars within the joint is satisfactory, we should choose tests with good anchorage. Unfortunately, most of the existing tests of beam-column subassemblages available to the author had poor anchorage of beam bars except the following four specimens:

(a) Unit 1 by Park and Milburn (1)

(b-1) Specimen C2 by Kitayama et al (4),

(b-2) Specimen C3 by Kitayama et al (5), and

(c) Specimen SWIO by Ichinose and Aoyama (6).

Details of these mecinens are listed in Table 1, where specimens $\mathrm{C} 2$ and $\mathrm{C} 3$ are listed in the same column because they are almost identical except that the ratio of horizontal joint shear reinforcement, $\mathrm{p}_{\mathrm{w}}=\mathrm{A}_{\mathrm{j} h} /\left(\mathrm{b}_{\mathrm{c}} \mathrm{j}_{\mathrm{b}}\right)$, of specimen $\mathrm{C} 3$ is about twice of that of specimen $\mathrm{C} 2$. Characteristic data are underlined. In this table $f_{y}$ indicates the measured yield strength. The horizontal joint shear force, $V_{j h}$, was calculated with Eq. (4), assuming that the steel strength enhancement factor, $\lambda$, was 1.1 and estimating the column shear with

$$
v_{c 01}=\frac{j_{b} / L_{c}}{1-\left(h_{c} / L_{b}\right)}\left(T_{1}+T_{2}\right)
$$

The tensile and compressive forces of the column bars, $\mathrm{T}_{\mathrm{C}}$ and $\mathrm{C}_{\mathrm{SC}}$, of this table were calculated by the plane section analysis assuming that both the column steel and concrete were linearly elastic and the modulus of elasticity of concrete was $1 / 15$ of that of steel and ignoring the tensile strength of concrete. This assumption is identical with that of the current Japanese code (7) to calculate allowable bending moment at a column section. This assumption would be justified because the compressive strain of the column concrete obtained by this analysis was small enough. In the actual 
TABLE 1 - TEST SPECIMENS FOR VERIFICATION

\begin{tabular}{|c|c|c|c|}
\hline REFERENCE & PARK & KITAYAMA & ICHINOSE \\
\hline Specimen & Unit 1 & $\mathrm{C} 2 \quad[\mathrm{C} 3]$ & SW10 \\
\hline $\begin{array}{l}\text { Concrete : } f_{C}^{\prime} \quad(\mathrm{MPa}) \\
\text { Beam }\end{array}$ & 41.3 & 25.6 & 27.3 \\
\hline$: L_{b} \quad(m m)$ & 5740 & 2700 & 2480 \\
\hline Section : $b_{b} \quad(\mathrm{~mm})$ & 229 & 200 & 200 \\
\hline$: h_{b} \quad(m m)$ & 457 & 300 & 300 \\
\hline$: j_{b}(m m)$ & 345 & 240 & 240 \\
\hline Top bars & $8-D 16$ & $12-D 10$ & $4-D 13$ \\
\hline$: p_{t}\left(\frac{o}{0}\right)$ & 1.75 & 1.59 & 0.94 \\
\hline$: f_{y} \quad(M P a)$ & 315 & 320 & 331 \\
\hline Bottom bars & same & $6-\mathrm{D} 10$ & same \\
\hline$: p_{t}\left(\frac{\circ}{0}\right)$ & as & 0.79 & as \\
\hline $\begin{array}{l}\because \\
\text { Column }\end{array}$ & top & 320 & top \\
\hline Span $\quad: L_{C} \quad(m m)$ & 3350 & 1470 & 1800 \\
\hline Section $: b_{C} \quad(m m)$ & 305 & 300 & 300 \\
\hline$: h_{C}(m m)$ & 406 & 300 & 400 \\
\hline$: j_{C}(m m)$ & 322 & 240 & 340 \\
\hline Ten. \& Comp. bars & $2-\mathrm{D} 24$ & $5-\mathrm{D} 13$ & $4-\mathrm{D} 13$ \\
\hline$: f_{y}(M P a)$ & 473 & 422 & 331 \\
\hline$: \mathrm{T}_{\mathrm{C}}^{1} / \mathrm{A}_{\mathrm{SC}} \mathrm{f}_{\mathrm{y}}$ & 0.80 & 0.50 & 0.46 \\
\hline$: \mathrm{C}_{\mathrm{SC}} / \mathrm{A}_{\mathrm{SC}} \stackrel{f}{\mathrm{f}}$ & 0.53 & 0.30 & 0.26 \\
\hline $\begin{array}{l}\text { Axial Load: } \mathrm{P}_{\mathrm{e}} / \mathrm{A}_{\mathrm{g}} \mathrm{f}^{\prime} \\
\text { Joint }\end{array}$ & 0.100 & 0.077 & 0.072 \\
\hline Shear : $V_{j h} / A_{g} f_{C}^{\prime}$ & $\underline{0.192}$ & 0.160 & 0.095 \\
\hline Vertical bars & $2-D 24$ & $6-\mathrm{D} 13$ & $4-\mathrm{D} 13$ \\
\hline$: f_{y}(M P a)$ & 473 & 422 & 331 \\
\hline$: v_{s v}^{y} / A_{g} f_{c}^{\prime}$ & 0.084 & 0.140 & 0.051 \\
\hline Horizontal bars & $16-\mathrm{R} 16$ & $20-D 6$ & $20-D 6$ \\
\hline$: \mathrm{p}_{\mathrm{W}}$ (\%) & 3.06 & $0.89[2.01]$ & 0.89 \\
\hline$: \mathrm{f}_{\mathrm{y}} \quad(\mathrm{MPa})$ & 320 & $324[330]$ & 370 \\
\hline $\mathrm{v}_{\mathrm{sh}} / \mathrm{V}_{\mathrm{jh}}$ given & 1.05 & $0.56 \quad[1.26]$ & 0.76 \\
\hline $\begin{array}{l}\mathrm{v}_{\mathrm{sh}} / \mathrm{v}_{j h} \text { meas'd } \\
\text { (ductility factor) }\end{array}$ & $\frac{0.78-1.06}{(4-6)}$ & $\frac{0.46}{(5)}[0.60]$ & $\begin{array}{r}? \\
(5)\end{array}$ \\
\hline $\mathrm{V}_{\mathrm{sh}} / \mathrm{V}_{\mathrm{jh}}$ proposed & 0.99 & 0.56 & $\underline{0.74}$ \\
\hline$v_{s h} / v_{j h} \quad N Z S$ & 1.00 & 1.00 & 1.00 \\
\hline
\end{tabular}

design, however, the designer may choose any methods in calculating $\mathrm{T}_{\mathrm{C}}$ and $\mathrm{C}_{\mathrm{SC}}$.

" $\mathrm{V}_{\mathrm{sh}} / \mathrm{V}_{j h}$ given" in this table indicates

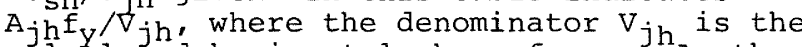
calculated horizontal shear force. As the ratios $\mathrm{P}_{e} / \mathrm{Ag}_{\mathrm{g}} \mathrm{f}^{\prime}$ are less than 0.1 in all the specimens, the current New Zealand code (1) requires $\mathrm{V}_{\mathrm{sh}} / \mathrm{V}_{\mathrm{ih}}=1.00$ as indicated in the last line of this table.

In the test of Unit 1 by Park et al (3), the tensile force in the horizontal joint shear reinforcement, $V_{s h}$, was measured by the strain gauges. The average of the measured ratio of $\mathrm{V}_{\mathrm{sh}} / \mathrm{V}$ jh (where the denominator $V_{j h}$ was also the measured value) was 0.78 at the second cycle of ductility factor \pm 4 . The ratio increased up to 1.06 when the ductility factor was \pm 6 . These data are indicated in the line $" \mathrm{~V}_{\mathrm{sh}} / \mathrm{V}_{j h}$ meas'd" in Table 1 . The ratios of $\mathrm{V}_{\mathrm{sh}} / \mathrm{V}_{j h}$ calculated by the proposed equation and the current $\mathrm{NZ}$ code (" $\mathrm{V}_{\mathrm{sh}} / \mathrm{V}_{j}$ prop'd" and " $\mathrm{V}_{\mathrm{sh}} / \mathrm{V}_{\mathrm{j}}$ NZS" in Table l) were about 1.0 which agreed with the measured ratios. 
The ratios $V_{s h} / V_{j h}$ was also measured in the test of the specimens $\mathrm{C} 2$ and $\mathrm{C} 3$ by Kitayama et al (4 and 5). The ratio was 0.46 and 0.60 for the specimens $\mathrm{C} 2$ and $\mathrm{C} 3$ at the first cycle of ductility factor about 5. (The ductility factor was calculated according to Park and Paulay (8).) The ratio $\mathrm{V}_{\mathrm{sh}} / \mathrm{V}_{j}$ calculated by the proposed equation, 0.56 , agreed with the measured ratio better than that by the current $\mathrm{NZ}$ code, 1.00. The main reasons why the proposed equation give a ratio much smaller than unity are:

(1) the amount of the top beam bars was twice that of the bottom, and

(2) the amount of the intermediate column bars was about three times of that required by the current $\mathrm{NZ}$ code.

In Specimen SWI0 tested by Ichinose et a] (6), the tensile force in the horizontal joint shear reinforcement, $V_{s h}$, was not measured. Judging from the crack distribution within the joint, however, the horizontal joint shear reinforcement did not yield even after the specimen was subjected to the cyclic loading of ductility factor about 5. So, we can assume that the proportion of the joint shear force carried by the horizontal joint shear reinforcement, $\mathrm{V}_{\mathrm{sh}} / \mathrm{V}_{j h}$, was less than 0.76 , "V $\mathrm{sh} / \mathrm{V}_{j} \mathrm{~h}$ given" in Table 1 . The ratio $\mathrm{V}_{\mathrm{sh}} / \mathrm{V}_{j h}$ calculated by the proposed equation, 0.74 , agrees with this test result better than that by the current $\mathrm{NZ}$ code. The main reasons why the proposed equation gives the ratio considerably smaller than unity are:

(1) the ratio $\left(\mathrm{P}_{e}+\mathrm{V}_{\mathrm{sy}}\right) / \mathrm{V}_{j h}$, the horizontal axis of Fig. 10, is as large as 1.3, and

(2) the distance between the extreme column bars is larger than that between the top and bottom bars $\left(j_{c} / j_{b}=1.4\right)$.

It would be valuable to examine the test results of specimen $\mathrm{Cl}$ of Kitayama et al (4). The dimensions and reinforcing details of specimen $\mathrm{Cl}$ are almost identical with those of specimens $\mathrm{C} 2$ and $\mathrm{C} 3$ except that the ratio of horizontal joint shear reinforcement, $p_{W}$, of specimen $C 1$ is $0.27 \%$. This ratio $\mathrm{p}_{w}$ is about one third of that required by the proposed equation (16). Strain of the shear reinforcement of this specimen $C l$ reached the yielding level when the flexural yielding of the beam bars was observed. The strain increased beyond the yielding level after the inelastic cyclic loadings. The shear deformation of the joint, however, was almost the same as those of specimens $\mathrm{C} 2$ and $\mathrm{C} 3$. Shear failure of the joint was not observed in specimen $\mathrm{Cl}$. The load deflection relationship of this specimen was spindle-shaped even at the loading excursion of ductility factor about 5. In short, the joint shear failure was prevented with shear reinforcement less than that required by the proposed equation (16).

A generalization of conclusions from the above observations is, however, not justified because of the following reasons:

Assume again that the bond forces of the beam bars within $j_{c}$ are uniformly dis- tributed as shown in Fig. 3. Then, the bond stresses of the top beam bar, tst, of specimen $\mathrm{Cl}$ (as well as $\mathrm{C} 2$ and $\mathrm{C} 3$ ) is:

$$
t_{s t}=\frac{T_{1}+T_{2}}{p_{s t} j_{c}}=\frac{1.5 \lambda f_{y} d_{b}}{4 j_{c}}=5.5
$$

where $P_{\text {st }}$ is the sum of the perimeter of the top beam bars and $d_{b}$ is the diameter of one beam bar. The bond stress of the bottom beam bar is:

$$
t_{\text {sh }}=\frac{2 T_{2}}{p_{s b} j_{c}}=\frac{\lambda E_{y} d_{b}}{2 j_{c}}=7.3
$$

Both of these values are smaller than that of Unit 1 of Park et al (3) where $t_{\text {st }}=t_{\text {st }}$ $=8.6(\mathrm{MPa})$. Further, the ratio $\mathrm{h}_{\mathrm{C}} / \mathrm{d}_{\mathrm{b}}$ of
specimen $\mathrm{Cl}$ is 30 , which is larger than the requirement of the current NZ code for grade 275 steel, $b_{c} / a_{b}<25$. Hence, it is probable that the bond stresses $t_{\text {st }}=5.5 \mathrm{MPa}$ and $t_{\mathrm{sb}}=7.3 \mathrm{MPa}$ in specimen $\mathrm{Cl}$ were considerably smaller than the bond strength.

If so, the distribution of bond stress needs not be uniform as shown in Fig. 3 . One possibility is that the bond stress is large where the beam bars are in compression and is small where the beam bars are in tension. This deviation of bond stress in the compression zone could be carried by a strut mechanism shown in Fig. 12, which does not need hoop action. Such a redistribution of bond stress requires horizontal strain along the beam bar, which might induce yielding of the horizontal joint shear reinforcement.

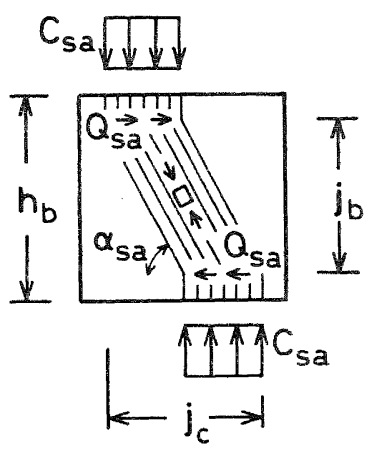

FIG. 12 - ALTERNATIVE STRUT ACIION DUE TO NON-UNIFORM BOND FORCE, Q sa

It should be noted that the strut mechanism of Fig. 12 can be realized when the average bond stresses of the beam bars are smaller than the bond strength. Therefore, reduction of horizontal joint shear reinforcement based on the strut mechanism of Fig. 12 requires the ratio of $h_{C} / d_{C}$ to be larger than the minimum specified. 


\section{CONCLUSIONS}

(1) The principle of the equilibrium of stress as well as a simplification of stress distribution along the periphery of the joint can yield a design equation (16) for inelastic interior joint.

(2) Normally, this design equation requires smaller amount of shear reinforcement than the current NZ code, especially for the following cases:

a) the joint shear stress is small,

b) the axial force is small,

c) the amount of top beam reinforcement is larger than at the bottom, and

d) the amount of vertical joint shear reinforcement is large.

(3) The proposed design equation agrees with results from the following two tests which seemed to contradict each other:

a) Park and Milburn (3) concluded that the current $\mathrm{NZ}$ code requirement was not overly conservative, and

b) Kitayama etal (5) concluded that one half of the shear reinforcement required by the current $\mathrm{NZ}$ code was enough to keep the joint elastic.

\section{ACKNOWLEDGEMENTS}

A major part of this study was done when the author was a visitor at the University of Canterbury from July 1985 to January 1986. Grateful thanks are due to valuable support. discussions and encouragement by professors R. Park and T. Paulay. The author also thanks Professor S. Otani of the University of Tokyo for several suggestions.

\section{REFERENCES}

1. NZS 3101:1982, "Code of Practice for the Design of Concrete Structures", Standards Association of New Zealand, Wellington, Part 1, 127 pp. Part 2, Illpp.

2. Paulay, T., Park, R., and Priestley, M.J.N.," "Reinforced Concrete BeamColumn Joint Under Seismic Actions", Journal of the American Concrete Institute, Proceedings, Vol.75, No.11, Nov. 1978, pp. 585-593.

3. Park, R. and Milburn, J.R., "Comparison of Recent New Zealand and United States Seismic Design Provisions for Reinforced Concrete Beam Column Joints and Test Results from Four Units Designed According to the New Zealand Code", Bulletin of the New Zealand National Society for Earthquake Engineering, Vol.16, No. 1, March 1983, pp.3-24.

4. Kitayama, K., Kurusu, K., Otani, S. and Aoyama, H.," "Improved Bond of Beam Bars and Hysteretic Behaviour for $\mathrm{R} / \mathrm{C}$ Interior Beam-Column Subassemblages", Proceedings of Annual Meeting of Architectural Institute of Japan, Oct. 1985, pp.293-294, (in Japanese).

5. Kitayama, K., Kurusu, K., Otani, S. and Aoyama, H., "Behaviour of BeamColumn Connections with Improved Beam Reinforcement Bond", Transaction of the Japanese Concrete Institute, Vol.7 1985 , pp. 551-558.

6. Ichinose, T., Aoyama, H. and Kai, Y., "Experimental Study on Seismic Behavior of Reinforced Concrete Subassemblages with Slitted Spandrel Walls", Proceedings of 8 th World Conference on Earthquake Engineering, Vol.6, July 1984, pp. $469-476$.

7. Architectural Institute of Japan, "Building Code Requirements and Commentary for Reinforced Concrete Structures, 1982", Architectural Institute of Japan, Tokyo, 685pp. (in Japanese) .

8. Park, R., and Paulay, T., "Reinforced Concrete Structures", John Wiley and Sons, New York, 1975, 769pp.

\section{APPENDIX 1 HOOP ACTIONS OUTSIDE THE} EXTREME COLUMN BARS

The assumption in the quasi strut action $A$ that the hoop action, $V_{\text {gar }}$, works directly on the left beam face as shown in Fig. $7(a)$ can be justified as follows:

The upper left corner of Fig. 7 (a) is enlarged and shown in Fig. 13(a).

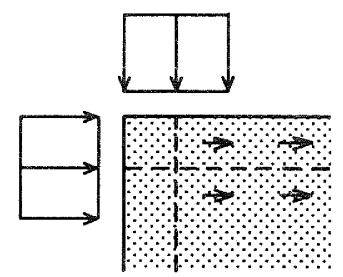

(a) Quasi strut

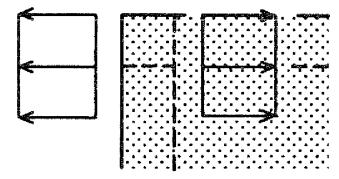

(b) Tensile stress

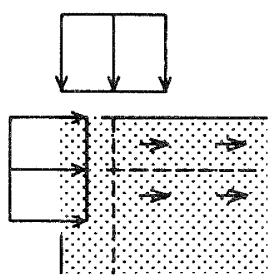

(c) Plausible state

FIG. 13 - TENSILE STRESSES DUE TO QUASI STRUT ACTION 
The broken lines indicate the location of the column and beam bars. The actual hoop action must be as shown in Fig. 13(c). Because of its anchorage, forces from the horizontal joint shear reinforcement must be applied where hoops enclose column bars. As a summation of Figs. 13(a) and (13b) equals Fig. 13(c), the tensile stress in Fig. 13(b) is required to sustain the quasi strut action of Fig. 13(a). This tensile stress is incompatible with the assumption that the concrete does not carry any tensile stress. We should note, however, that the beam bars in this region carry a large amount of compressive force, which would cancel the tensile stress shown in Fig.

13(b). Therefore, the quasi strut action of Fig. I3(a) or Fig. $7(b)$ will be sustained.

We can also justify the assumption with regards to the bond action in Fig. 7 (b) that the hoop action $\mathrm{V}_{\mathrm{ga}}$ is applied directly on the right beam face. The assumed hoop action $V_{\text {ga }}$ of Fig. $7(b)$ equilibrates with the bond stresses of the beam bars distributed between the external column bars, as shown in Fig. 3. So, hoop action between the external column bars can constitute the bond action of Fig. $7(b)$.

\section{APPENDIX 2 HOOP ACTIONS IN ADJACENT COLUMNS}

We can justify the assumption in equation (14) that hoop actions above the top and below the bottom beam bars exist.

As long as the columns are elastic, so that the flexural cracks between the columns and the joint are narrow enough, the bond stresses of the beam bars can flow into the neighbouring columns as shown in Fig. 14. The stress flow in Fig. 14 does not impede the shear stress flow within the columns, shown in Fig. 15. The stress flow in Fig. 14 does not impede the flexural confinement of concrete by the hoop reinforcement around the compressive regions of the columns, either. Therefore, the stress flow of Fig. 14 should be acceptable.

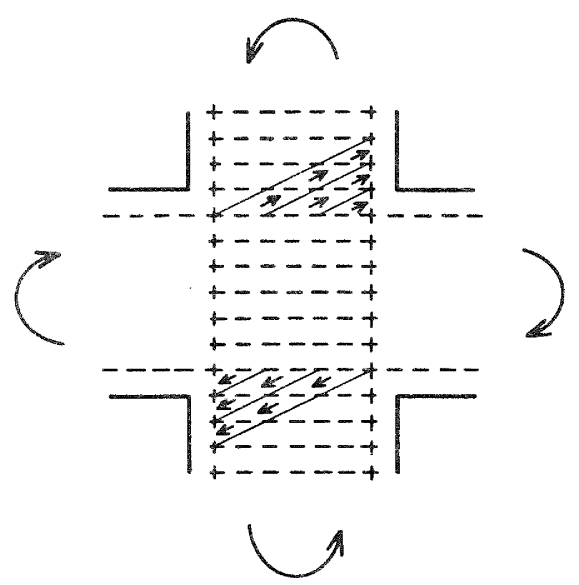

FIG. 14 - FLOW OF BOND STRESSES INTO ADJACENT COLUMNS

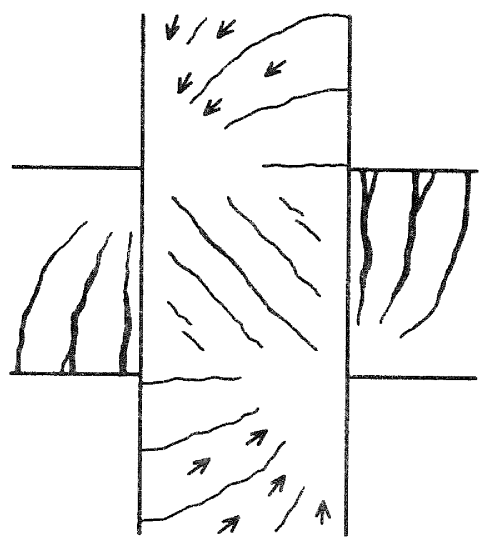

FIG. 15 - FLOW OF SHEAR STRESSES WITHIN COLUMNS

\section{APPENDIX 3 NOTATION}

A : Gross concrete area of column section $\left(=b_{c} h_{c}\right)$

$A_{j h}, A_{j v}$ : Total area of horizontal and vertical joint shear reinforcement, respectively

$A_{s t}, A_{s b}$ : Area of top and bottom beam reinforcement

$\mathrm{b}_{\mathrm{c}}$ : Width of column

$c_{c}$ : Eccentric component of column concrete compressive stresses

$\mathrm{C}_{\mathrm{Cl}}$ : Compressive force in beam concrete around top beam bars $\mathrm{C}_{\text {qa }}$ : $\begin{aligned} & \text { Part of } \mathrm{C}_{\mathrm{C}} \text { constituting the quasi } \\ & \text { strut action } \mathrm{A}\end{aligned}$

$C_{q b}$ : Part of $C_{C}$ constituting the quasi strut action $B$

$\mathrm{C}_{\mathrm{sl}}$ : Compressive force in bottom beam bars

$\mathrm{C}_{\mathrm{s} 2}$ : Compressive force in top beam bars

$\mathrm{C}_{\text {sa }}$ : Component of column concrete compressive stresses constituting an alternative strut action

$\mathrm{C}_{\mathrm{SC}}$ : Compressive force in column bars

$f_{C}^{\prime}$ : Compressive strength of concrete

$f_{y}$ : Yield strength of steel

$h_{b}, h_{c}$ : Depth of beam and column respectively

$j_{b}$ : Distance between top and bottom beam bars

$j_{c}$ : Distance between extreme column bars

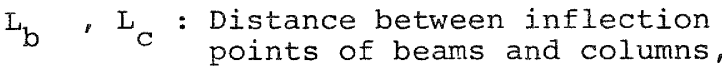
respectively

$\mathrm{P}_{\mathrm{e}}$ : Column applied axial load

$\mathrm{P}_{\mathrm{ev}}$ : Concentric component of column concrete compressive stresses

$\mathrm{P}_{t}$ : Ratio of beam tension reinforcement 


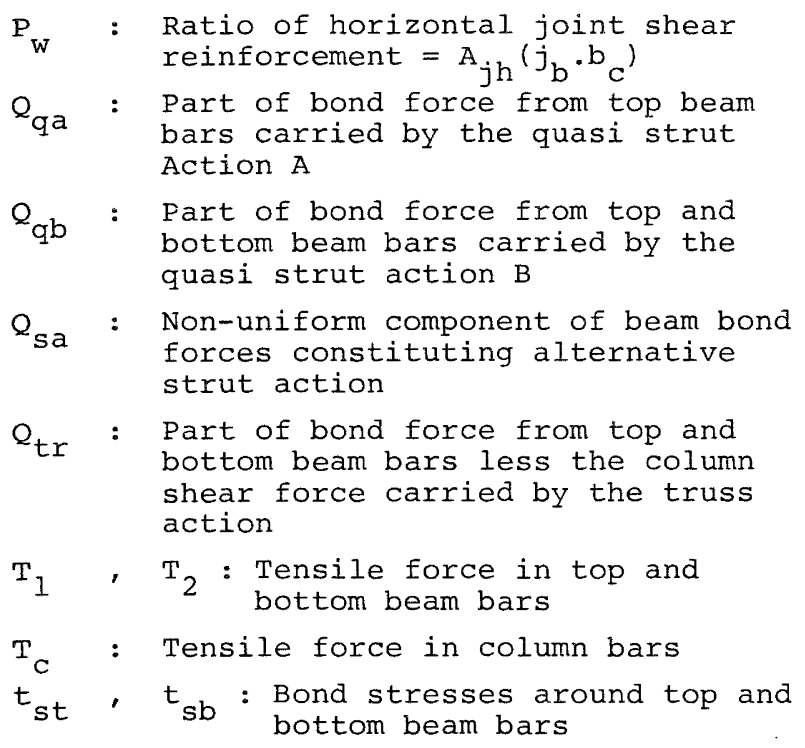

$$
\begin{aligned}
\mathrm{v}_{\mathrm{b}}, \mathrm{v}_{\mathrm{col}}: \begin{array}{l}
\text { Beam and column shear forces } \\
\text { respectively }
\end{array} \\
\mathrm{v}_{j \mathrm{~h}}, \mathrm{v}_{j \mathrm{v}:}: \begin{array}{l}
\text { Horizontal amd vertical joint } \\
\text { shear force }
\end{array} \\
\mathrm{v}_{\mathrm{qa}}, \mathrm{v}_{\mathrm{qb}}: \begin{array}{l}
\text { Part of hoop action in quasi } \\
\text { strut actions A and } \mathrm{B}
\end{array} \\
\mathrm{v}_{\mathrm{sh}}, \mathrm{v}_{\mathrm{sv}}: \begin{array}{l}
\text { Tensile force carried by } \\
\text { horizontal and vertical joint } \\
\text { shear reinforcement }
\end{array}
\end{aligned}
$$

$\alpha$ : Inclination of concrete compressive stress in truss action

$\lambda$ : Steel strength enhancement factor

$\sigma$ : Concrete compressive stress in truss action

$\tau$ : Concrete shear stress in truss action 